\title{
Validation of a hemiacetal intermediate during absolute Soai autocatalytic amplification under heterogenous phase
}

\author{
Giuseppe Rotunno ${ }^{a, b}$ and Mohamed Amedjkouh *a,b
}

a'Department of Chemistry, University of Oslo, P.O. Box 1033, Blindern, 0315 Oslo, Norway

${ }^{b}$ Center for Materials Science and Nanotechnology (SMN), Faculty of Mathematics and Natural Sciences, University of Oslo, P.O. Box 1126, Blindern, 0318 Oslo, Norway

E-Mail: mamou@kjemi.uio.no

Absolute asymmetric synthesis produces chiral molecules without any chiral polarization and is an interesting rational for the origin of homochirality. Remarkably, in the Soai reaction absolute asymmetric amplification of alkanol product is observed under heterogenous conditions. Reaction of $\mathrm{ir}_{2} \mathrm{Zn}$ vapor on solid carbaldehyde produced corresponding alkanol with up to $96 \% \mathrm{ee}$. In a parallel amplification process, a chiral ester is produced with $98 \%$ ee. The latter is attributed to disproportionation of starting aldehyde into hemiacetal followed by a subsequent Claisen-Tishchenko mechanism. This observation provide evidence for the debated transient intermediate, and opens new perspectives in the elucidation of the mechanism of amplification of chirality in the Soai reaction. 
Despite the still intriguing origin of homochirality, ${ }^{[1]}$ recent work provided enantioenrichment (ee) without any chiral bias from achiral precursors, i.e. absolute asymmetric synthesis. ${ }^{[2]}$ Single phase homochirality without counter enantiomer nucleation may also be accessed through enhanced deracemization. ${ }^{[3]}$ Small amount of chiral induction by circularly polarised light (CPL) can be amplified into an enantiopure solid phase. ${ }^{[4]}$.The Soai reaction represents a remarkable example of an absolute asymmetric catalysis in the alkylation of pyrimidinyl aldehyde $\mathbf{1}$ into alkanol 2, giving rise to homochirality without the intervention of any chiral factor (Scheme 1a). ${ }^{[1 a, 5]}$. Key to propagation of asymmetric amplification is that classical statistical fluctuation in the enantiomeric ratio by virtue of non-linear relationship (NLE) of catalyst-product pair, in the form of a homochiral aggregate species in conjunction with autocatalysis. ${ }^{[6]}$ Recently, asymmetric amplification of such autocatalysts was realized via a heterogeneous vapour-solid interaction by reaction of $\mathrm{iPr}_{2} \mathrm{Zn}$ vapor on achiral solid aldehyde. ${ }^{[7]}$

a) Absolute Asymmetric synthesis under homogenous and heterogenous conditions

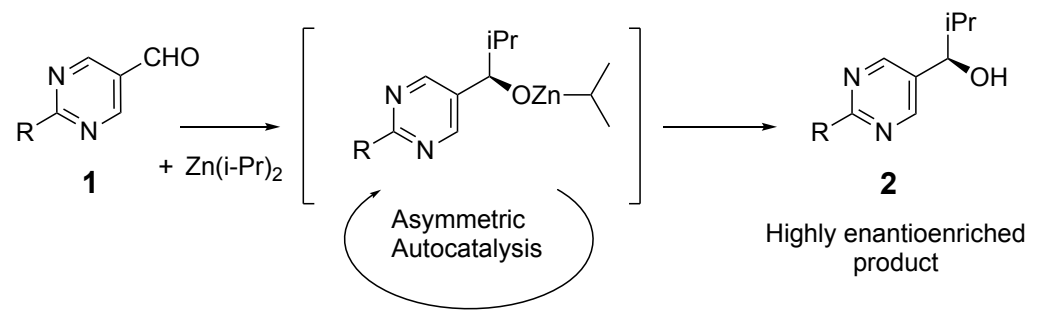

b) Observed transient hemiacetal

c) Observed chiral ester subsequent to hemiacetal

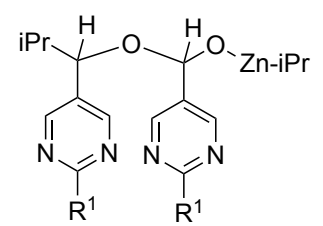

$\mathrm{R}^{1}=$ Adamantyl $=\xi$

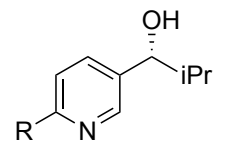

3

$$
\mathrm{R}=\mathrm{t}-\mathrm{Bu} \rightleftharpoons \underline{\overline{ }}
$$

d) This work: Chiral Ester from Achiral Heterogenous Conditions

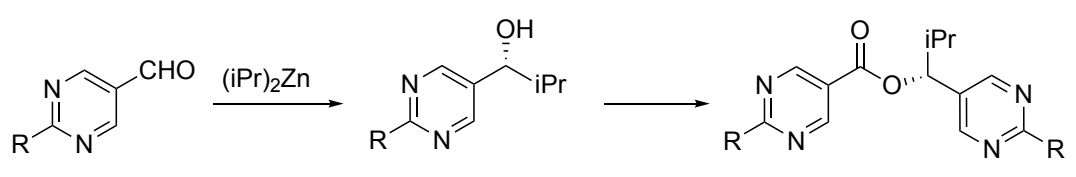

1

2

5

Scheme 1.: a) Absolute asymmetric synthesis initiated by symmetry breaking

b) Observed transient hemiacetal by Brown et al. c) Isolated chiral ester derived from hemiacetal intermediate in recent work. d) Observation of chiral ester derivative in the Soai reaction. 
During our investigations, in addition to the main chiral alkanol 3, other side-products were observed. Notably, we isolated the pyridine derived chiral ester 4 with $83 \%$ ee after amplification following symmetry breaking (Scheme 1c). We reasoned that formation of ester is consistent with a Claisen-Tishchenko rearrangement of hemiacetal intermediate. ${ }^{[\mathrm{b}]}$ However, ester derivative was not reported in the corresponding studies of Soai reaction of 1 . We report the observation of chiral pyrimidinyl-ester $\mathbf{5}$ thus validating the formation of intermediate hemiacetal during amplification of alkanol $\mathbf{2}$ under heterogenous conditions. To avoid confusion, we will not discuss absolute configurations o enantiomers because of their random distribution.

Hemiacetal complexes are proposed in an alternative mechanism for amplification. Brown et al. first observed this transient intermediate, during ${ }^{1} \mathrm{H} N M R$ spectroscopy monitoring of the reaction at $0{ }^{\circ} \mathrm{C}$, and identified it as an alkoxyacetal formed from one aldehyde and two alkoxide moieties (Scheme 1b). ${ }^{[61,8]}$ Moreover, based on in-situ highresolution mass spectrometric investigations and kinetic analyses, Trapp et al. reported observation of the transient hemiacetal complexes, and proposed their implications in a autocatalytic mechanism. ${ }^{[9]}$

Chiral hemiacetals have been reported in intramolecular condensation of Zn-alkoxides during monoalkylation of dialdehyde with $\mathrm{Et}_{2} \mathrm{Zn} .{ }^{[10]}$ Further oxidation of hemiacetal would lead to the corresponding chiral ester. ${ }^{[11]}$ More recent work revealed an intraand intermolecular Claisen-Tishchenko catalysed by metallic zinc. ${ }^{[12]}$

We first defined overall experimental details based on our previous report, and began our studies by examining the behavior of pyrimidine-5-carboxaldehyde 1 upon action of $\mathrm{i}-\mathrm{Pr}_{2} \mathrm{Zn}$ under heterogenous conditions. To perform the Solid-vapor phase absolute asymmetric synthesis, solid $\mathbf{1}$ and $\mathrm{i}-\mathrm{Pr}_{2} \mathrm{Zn}$ solution in toluene were placed at separated positions in a vial under Ar atmosphere. ${ }^{[7 b]}$ In contrast to our recent findings on the studies of pyridinyl aldehyde, acetal derivative, i.e., chiral ester 5, was not reported in the corresponding Soai reaction of 1 with large excess of $\mathrm{iPr}_{2} \mathrm{Zn}$ vapour\{Kaimori, 2019 \#220\} (Scheme 1d) in the few studies under heterogenous conditions. In solution, it was established that the Soai reaction performed best in presence of 2 equivalents of $\mathrm{iPr}_{2} \mathrm{Zn}$ with respect to aldehyde 1. Because formation and amplification of alkanol 2 may be related to diffusion of $\mathrm{iPr}_{2} \mathrm{Zn}$ vapour, in contrast to homogenous reaction 
conditions, we questioned the possible influence of the local concentration of the alkylating reagent available at the surface of solid aldehyde. Therefore, under heterogenous conditions, initial experiments were conducted with 2 equivalents of $\mathrm{iPr}_{2} \mathrm{Zn}$ vapor on solid Soai aldehyde 1 at room temperature.
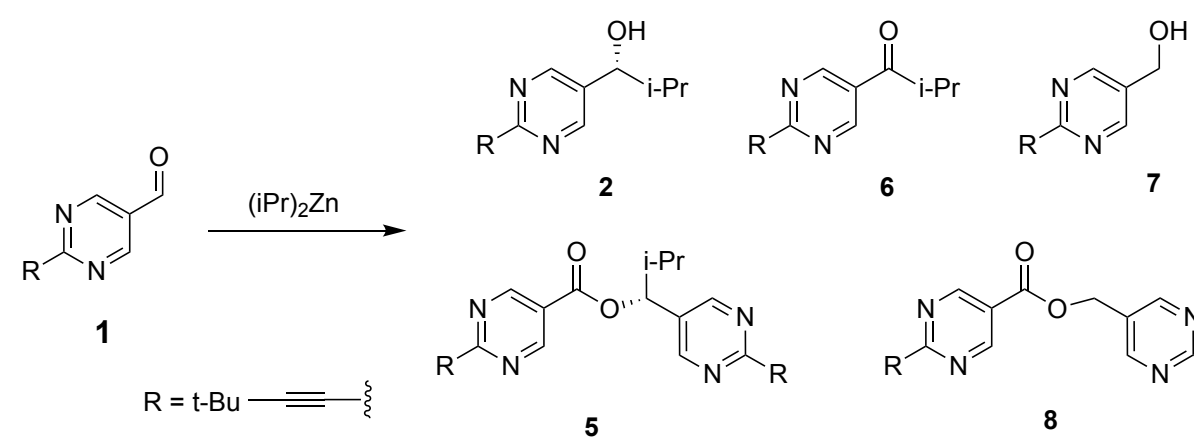

6

7
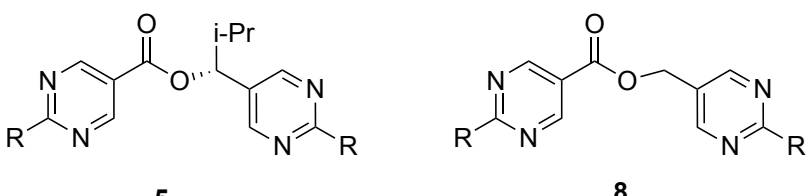

8

Scheme 2. Products of the vapour solid reaction of 1 and $i \mathrm{Pr}_{2} \mathrm{Zn}$.

Analysis of crude NMR spectra allowed identification of related compounds (side products) consisting of ketone 6 and chiral ester resulting from alkylation of aldehyde, in line with our previous observations. In addition, the reaction also provided achiral esters 8 rising from reduction alkanol 7. These compounds are analogous to those previously observed in the reaction of pyridyl aldehyde, following the ClaisenTishchenko rearrangement. However, the side products are not observed in all cases. Therefore, sets of experiments were conducted for aldehyde 1 with varying concentration of $\mathrm{iPr}_{2} \mathrm{Zn}$ for a period of $72 \mathrm{~h}$. Interestingly, when the reaction was performed with lower loading of $\mathrm{iPr}_{2} \mathrm{Zn}$ the same side products were identified, even

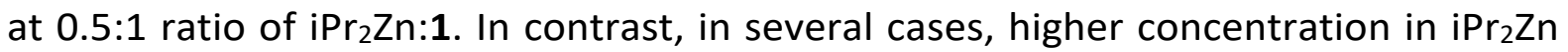
delivered exclusively alkanol $\mathbf{2}$ as the sole product.

The general features of this reactivity were reproduced for several samples. A closer look, at ${ }^{1} \mathrm{H}$ NMR the crude reveals the presence of other signals in addition to those arising from alkanol 2 (4.50 ppm). A doublet at $5.7 \mathrm{ppm}$ stems from a proton on an isopropyl group revealing build-up of chiral ester $\mathbf{5}$, while a signal at $3.5 \mathrm{ppm}$ indicates formation of ketone 6 (Scheme 2). Besides, a signal at $4.78 \mathrm{ppm}$ was assigned to the vicinal protons of the alcohol 7 rising from reduction of aldehyde 1 . Notably, ${ }^{1} \mathrm{H}$ NMR 
shows that at lower ration $0.5: 1$ of $\operatorname{Pr}_{2} Z n: 1$ chiral ester 5 increased at the expense of the major chiral 2.

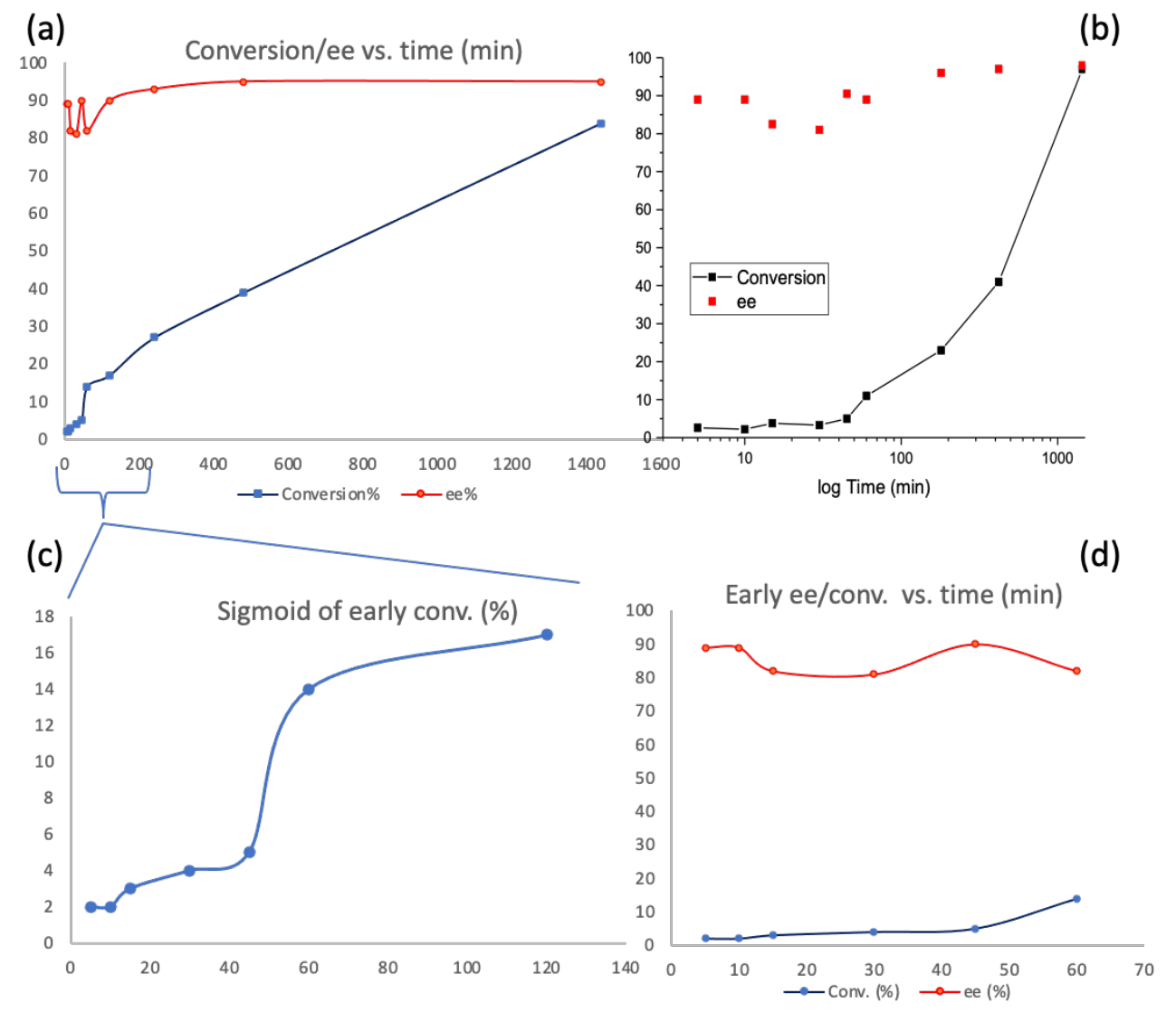

Figure 1: Conversion and ee\% of vapour phase reaction on aldehyde $3 c$ between 5 minutes and 24 hours

A typical feature of autocatalysis is a sigmoidal product/time curve and an induction period. Additional experiments focused therefore on the early stages of the reaction. To this end, a set of reactions were initiated simultaneously and stopped at fixed time interval.

Figure 1 presents the conversion and ee values obtained from the analysis on aldehyde 1 monitored as function of time, at 0.5:1 ratio of $\operatorname{iPr}_{2} Z n: 1$. Remarkably, at the outset, symmetry breaking was reflected in a sudden burst of very high ee, which evolved steadily while remaining constantly very high throughout all samples, in the range of $82-96 \%$ ee (Figure 1a). At about $10 \%$ conversion alkanol 2 is formed with $82 \%$ ee. Following advancement of the reaction at early rates reveals in the first leg (figure 1b) that conversion increased slowly over time. Also Figure $1 \mathrm{~b}$ shows a typical parabolic 
shape with a slow induction period followed by a fast increase of the conversion after the first 60 minutes. Although sampling rate remains difficult at this stage of the reaction, a sigmoidal shape is observed for the conversion during this interval, corroborating an autocatalytic process (Figure 1c). The corresponding ee measured for this portion shows an oscillation between 81 and 90\% (figure 1d). Nevertheless, the high ee values remained steady.

Table 1.1: Vapour phase reactions with different amount of $\mathrm{Pr}_{2} \mathrm{Zn}$

\begin{tabular}{cccccccc}
\hline \multirow{2}{*}{ Entry $^{a}$} & $\begin{array}{c}\text { Ratio } \\
\text { 1: } i \operatorname{Pr}_{2} Z n\end{array}$ & \multicolumn{7}{c}{ Molar ratio $^{b}$} \\
\cline { 3 - 8 } & & $\mathbf{1}$ & $\mathbf{2}$ & $\mathbf{5}$ & $\mathbf{6}$ & $\mathbf{7}$ & $\mathbf{8}$ \\
\hline 1 & $1: 2$ & 21 & 61 & 12 & 2 & 4 & $/^{c}$ \\
2 & $1: 1$ & 2 & 65 & 7 & 13 & 13 & $/^{c}$ \\
3 & $1: 0.5$ & 47 & 17 & 8 & 16 & 12 & $/^{c}$ \\
\hline
\end{tabular}

${ }^{a}$ All reactions have been performed using the same batch of 1 and $\operatorname{PPr}_{2} \mathrm{Zn}$ solution in Toluene at room temperature. Reaction set up under Ar atmosphere as previously reported (Ref. ${ }^{[7 b]}{ }^{b}$ Determined by $1 \mathrm{H}$ NMR spectroscopy on crude mixtures. ${ }^{c}$ Not measurable.

Table 1.2: ee values for 2 and 5

\begin{tabular}{cccc}
\hline Entry & $\begin{array}{c}\text { Ratio } \\
1: i \operatorname{Pr}_{2} Z \mathbf{Z n}\end{array}$ & $e e \% \mathbf{2}^{a}$ & $e \mathbf{5}^{b}$ \\
\hline 1 & $1: 2$ & 94 & 95 \\
2 & $1: 1$ & 95 & 94 \\
3 & $1: 0.5$ & 96 & 98 \\
\hline
\end{tabular}

${ }^{a}$ Determined using chromatography analysis on a chiral stationary phase. ${ }^{b}$ Determined by HPLC analysis of $\mathbf{2}$ after hydrolysis of ester 5 .

Beside the extent of side products formation, it was interesting to explore whether heterogenous amplification of alkanol $\mathbf{2}$ and ester $\mathbf{5}$ may be influenced by of $\mathrm{iPr}_{2} \mathrm{Zn}$ concentration. As shown in table 1.1, outcome of reactions after $72 \mathrm{~h}$ with different $\mathrm{iPr}_{2} \mathrm{Zn}$ loadings consistently provided alkanol 2 with $94-96 \%$ ee. Subsequently, ester $\mathbf{5}$ was formed with comparable enantiopurity in the range of $94-98 \%$ ee and with the same absolute configuration as $\mathbf{2}$. These measurements required hydrolysis of $\mathbf{5}$ due to difficult separation of its enantiomers on HPLC. As we reported previously, chiral ester $\mathbf{5}$ forms in a two steps mechanism by a Cannizaro disproportionation of aldehyde 1 followed by a Claisen-Tishchenko rearrangement. ${ }^{[7 b, 13]}$ Amplification of 5 ensues by 
reversible hemiacetal formation, in two diastereomers with a kinetically preferred intermediate converting into ester. ${ }^{[14]}$

In order to delineate a sequence for the formation of the different compounds during the autocatalytic process, the reaction of 1 with $i \operatorname{Pr}_{2} Z n$ in a 1:0,5 product formation was monitored vs. time by a series of runs. The low concentration of $\mathrm{iPr}_{2} \mathrm{Zn}$ was preferred in order to allow slow diffusion over solid aldehyde 1. Our hypothesis relies on the mechanism suggested in our previous report for the formation of a chiral ester facilitated under heterogenous conditions by keeping a low concentration of $\mathrm{iPr}_{2} \mathrm{Zn}$ overtime. In such a way, forming $\mathrm{Zn}$-alkoxide is trapped upon reaction with "surrounding" excess aldehyde to generate the hemiacetal intermediate, which then disappears by converting into ester. As standard conditions, aldehyde was reacted in presence of $\mathrm{iPr}_{2} \mathrm{Zn}$ for a period varying from 3 to $72 \mathrm{~h}$, and product isolated at the end for each run. After in-situ work up samples were withdrawn from crudes and analysed by ${ }^{1} \mathrm{H}$ NMR and subsequently essayed for enantiopurity by chiral HPLC.

Generally, the series of NMR experiments exhibited unpredictable rates and ratios for product formation. The results show a steady decay of aldehyde $\mathbf{1}$ along with forming alkanol $\mathbf{2}$ and reduction alkanol $\mathbf{7}$ already in the early stages of the reaction (Figure 2). Subsequently, 5, 6 and 8 were detected only after 24 hours.

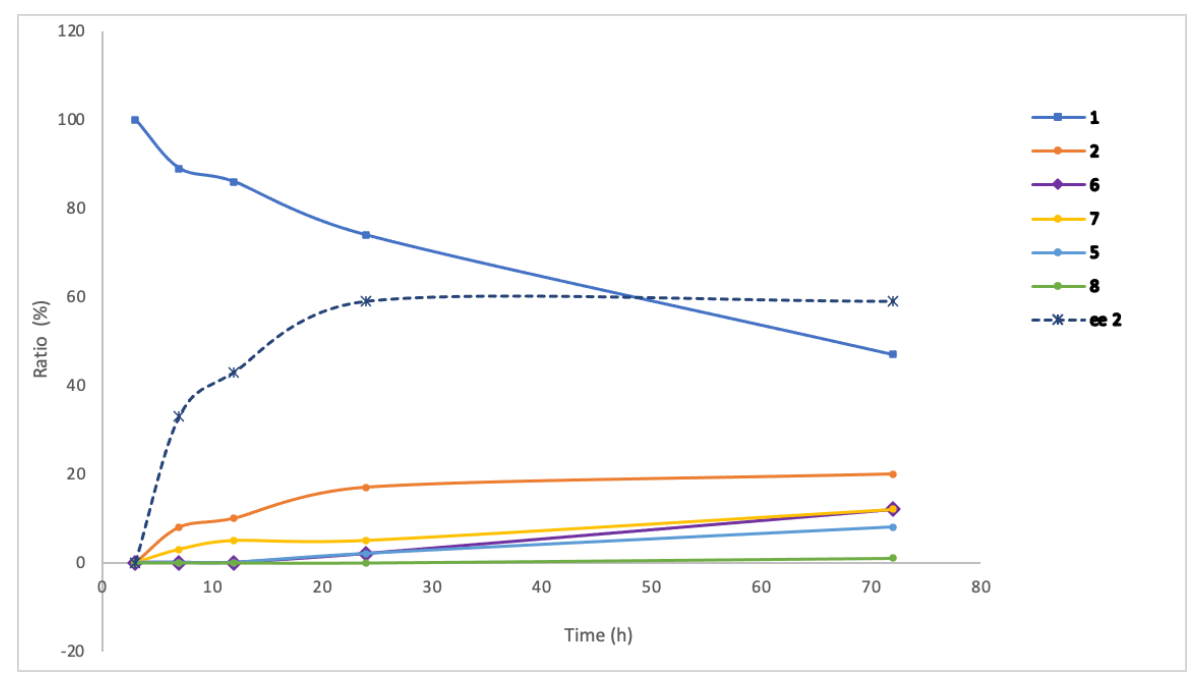

Figure 2: Kinetic experiment on the vapour phase reaction with a 1:0,5 ratio of 1 to $\mathrm{iPr}_{2} \mathrm{Zn}$. 
Likewise, enantiopurity was examined for all samples at time intervals shown in figure 2, which reveals a firm increase of ee during the whole process confirming amplification of chirality. Again, the figure shows an early and significant rise of handedness with a first recording at $34 \%$ ee after $7 \mathrm{~h}$ of reaction and very low conversion. Asymmetric amplification of $\mathbf{2}$ increased less gently to a maximum of 59\% ee for $20 \%$ of alkanol 2. Naturally the deficiency in $\mathrm{iPr}_{2} \mathrm{Zn}$ caused a very low conversion and consequently limited amplification of chirality. Notably, the perceived behaviour is not unique to the present study and adheres to a trend described in our preceding reports.

\section{Conclusions}

In summary, the event of a Claisen-Tishchenko rearrangement provided a direct evidence for a transient hemi-acetal intermediate in the Soai autocatalytic amplification. Under our experimental conditions, reaction of $\mathrm{PPr}_{2} \mathrm{Zn}$ vapour on solid aldehyde $\mathbf{1}$ delivered highly enantiopure alkanol $\mathbf{2}$ and corresponding chiral ester $\mathbf{5}$. Handedness arose rapidly in up to $96 \%$ and $98 \%$ ee, respectively. Although with varying amounts, all runs with low loading of $\mathrm{iPr}_{2} \mathrm{Zn}$ provided ester $\mathbf{5}$. This is in agreement with previous observation of transient Soai acetal in solution, favoured by initial concentration of aldehyde 1 . Indeed, under heterogenous conditions and slow diffusion of $\mathrm{iPr}_{2} \mathrm{Zn}$ vapour, excess aldehyde is retained throughout the process which allows trapping of $\mathrm{Zn}$-alkoxide in the form of acetal equilibrium mechanism. The present results provide new insight into possible intermediates involved in the amplification of chirality.

This work was financially supported by the Research Council of Norway (TOPFORSK program 250795), the University of Oslo, and COST Action "Emergence and Evolution of Complex Chemical Systems" (CM 1304).

\section{Conflicts of interest}

There are no conflicts to declare. 


\section{Notes and references}

1 [1] a) K. Mislow, Collect. Czech. Chem. Commun. 2003, 68, 849-864; b) M. Bolli, R. Micura and A. Eschenmoser, Chemistry \& Biology 1997, 4, 309-320; c) B. L. Feringa and R. A. van Delden, Angewandte Chemie-International Edition 1999, 38, 34193438; d) S. Pizzarello and A. L. Weber, Science (Washington, DC, U. S.) 2004, 303, 1151; e) I. Weissbuch and M. Lahav, Chem. Rev. (Washington, DC, U. S.) 2011, 111, 3236-3267; f) J. S. Siegel, Chirality 1998, 10, 24-27; g) J. M. Ribo, C. Blanco, J. Crusats, Z. El-Hachemi, D. Hochberg and A. Moyano, Chem. - Eur. J. 2014, 20, 17250-17271.

2 [2] a) T. T. Mai, M. Branca, D. Gori, R. Guillot, C. Kouklovsky and V. Alezra, Angew Chem Int Ed Eng/ 2012, 51, 4981-4984; b) S. Olsson, A. Lennartson and M. Hakansson, Chemistry-a European Journal 2013, 19, 12415-12423; c) A. Lennartson, S. Olsson, J. Sundberg and M. Hakansson, Angewandte Chemie-International Edition 2009, 48, 3137-3140.

3 [3] a) D. K. Kondepudi, R. J. Kaufman and N. Singh, Science 1990, 250, 975-976; b) C. Viedma, Physical Review Letters 2005, 94; c) P. M. Bjoremark, J. Jonsson and M. H. Hakansson, Chemistry-a European Journal 2015, 21, 10630-+; d) P. M. Bjoremark, S. Olsson, T. Kokoli and M. Hakansson, Chemistry-a European Journal 2015, 21, 87508753.

4 [4] a) W. L. Noorduin, T. Izumi, A. Millemaggi, M. Leeman, H. Meekes, W. J. P. Van Enckevort, R. M. Kellogg, B. Kaptein, E. Vlieg and D. G. Blackmond, Journal of the American Chemical Society 2008, 130, 1158-+; b) W. L. Noorduin, A. A. C. Bode, M. van der Meijden, H. Meekes, A. F. van Etteger, W. J. P. van Enckevort, P. C. M. Christianen, B. Kaptein, R. M. Kellogg, T. Rasing and E. Vlieg, Nature Chemistry 2009, 1, 729-732.

5 [5] a) K. Soai, T. Shibata, H. Morioka and K. Choji, Nature (London) 1995, 378, $767-$ 768; b) T. Shibata, S. Yonekubo and K. Soai, Angew. Chem., Int. Ed. 1999, 38, 659661; c) I. Sato, H. Urabe, S. Ishiguro, T. Shibata and K. Soai, Angew. Chem., Int. Ed. 2003, 42, 315-317.

6 [6] a) E. Doka and G. Lente, J. Am. Chem. Soc. 2011, 133, 17878-17881; b) O. Fulop and B. Barabas, J. Math. Chem. 2016, 54, 10-17; c) B. Barabas, R. Kurdi, C. Zucchi and 
G. Palyi, Chirality 2018, 30, 913-922; d) B. Barabas, J. Toth and G. Palyi, J. Math. Chem. 2010, 48, 457-489; e) D. G. Blackmond, Tetrahedron: Asymmetry 2006, 17, 584-589; f) J.-C. Micheau, C. Coudret, J.-M. Cruz and T. Buhse, Physical Chemistry Chemical Physics 2012, 14, 13239-13248; g) A. J. Bissette and S. P. Fletcher, Angew. Chem., Int. Ed. 2013, 52, 12800-12826; h) F. C. Frank, Biochimica et Biophysica Acta 1953, 11, 459-463; i) D. G. Blackmond, Proc. Natl. Acad. Sci. U. S. A. 2004, 101, $5732-$ 5736; j) J. M. Brown, I. Gridnev and J. Klankermayer, Top. Curr. Chem. 2008, 284, 3565; k) I. D. Gridnev and A. K. Vorobiev, ACS Catal. 2012, 2, 2137-2149; I) T. Gehring, M. Quaranta, B. Odell, D. G. Blackmond and J. M. Brown, Angew. Chem., Int. Ed. 2012, 51, 9539-9542, S9539/9531-S9539/9541; m) S. V. Athavale, A. Simon, K. N. Houk and S. E. Denmark, Nature Chemistry 2020, 12, 412-423; n) T. Satyanarayana, S. Abraham and H. B. Kagan, Angew. Chem., Int. Ed. 2009, 48, 456-494.

7 [7] a) Y. Kaimori, Y. Hiyoshi, T. Kawasaki, A. Matsumoto and K. Soai, Chemical Communications 2019, 55, 5223-5226; b) G. Rotunno, D. Petersen and M. Amedjkouh, ChemSystemsChem 2020, 2, e1900060.

8 [8] I. D. Gridnev and A. K. Vorobiev, Bulletin of the Chemical Society of Japan 2015, $88,333-340$.

9 [9] O. Trapp, S. Lamour, F. Maier, A. F. Siegle, K. Zawatzky and B. F. Straub, Chemistry - A European Journal 2020, 26, 15871-15880.

$10[10]$ K. Soai, Y. Inoue, T. Takahashi and T. Shibata, Tetrahedron 1996, 52, 1335513362.

11 [11] M. Watanabe, N. Hashimoto, S. Araki and Y. Butsugan, The Journal of Organic Chemistry 1992, 57, 742-744.

12 [12] M. Miyagawa and T. Akiyama, Chemistry Letters 2018, 47, 78-81.

13 [13] a) L. Claisen, Ber. Dtsch. Chem. Ges. 1887, 20, 646-650; b) V. E. Tishchenko, J. Russ. Phys. Chem. Soc 1906, 38, 355-418; c) V. E. Tishchenko, J. Russ. Phys. Chem. Soc 1906, 38, 482-540; d) A. O. K. A. M. P. Koskinen in The Tishchenko Reaction, Vol. 86 2015, pp. 105-410.

14 [14] a) D. Drahoňovský and J.-M. Lehn, The Journal of Organic Chemistry 2009, 74, 8428-8432; b) L. You, J. S. Berman and E. V. Anslyn, Nature Chemistry 2011, 3, 943948. 